\title{
EL CASO DE GAYLE ${ }^{1}$
}

\author{
Hazel R. Ipp ${ }^{2}$ \\ Toronto, Canada
}

Se presenta el relato clínico elaborado por Hazel Ipp sobre "Gayle", junto a una transcripción de fragmentos de sesiones. Se propone una reflexión sobre el proceso psicoanalítico con el déficit narcisista, que será objeto de comentario.

Palabras clave: Narcisismo, Proceso psicoterapéutico

Hazel Ipp's clinical account of "Gayle" is presented, including a transcript of excerpts from sessions. A reflection on the psychoanalytic process with the narcissistic deficit is proposed, which will be the subject of comment.

Key Words: Narcissism, Psychotherapeutic process

English Title: The case of Gayle

\section{Cita bibliográfica / Reference citation:}

Ipp, H. (2021). El caso de Gayle. Clínica e Investigación Relacional, 15 (2): 341-351. [ISSN 1988-2939]

[Recuperado de www.ceir.info] DOI: 10.21110/19882939.2021.150202

\footnotetext{
${ }^{1}$ Publicado originalmente como: Ipp, H.R. (2001). The Case of Gayle. Progress in Self Psychology, 17:47-56. Traducción castellana de María Hernández Gázquez, revisada por Alejandro Ávila Espada. Caso presentado y comentado en la sesión del programa intensivo de formación en Psicoterapia Psicoanalítica Relacional el 8 de Mayo de 2021 en Ágora Relacional, Madrid.

${ }^{2}$ Hazel Ipp es Doctora en Psicología y Psicoanalista. Fundadora, Ex -presidenta y Miembro del Board de IARPP. Ejerce en Toronto, Canadá. Vice-Presidenta, Supervisora y Analista Didacta del Toronto Institute for Contemporary Psychoanalysis. Profesora del Institute for the Advancement of Self Psychology, de ISIPse (Roma). Profspra visitante del Psychoanalytic Institute of Northern California. Miembro de Honor del Instituto de Psicoterapia Relacional (Madrid). Editora de Psychoanalytic Dialogues y editora-corresponsal de la revista Contemporary Psychoanalysis.
} 
Gayle, mujer soltera de unos cuarenta años con una exitosa carrera en el mundo del arte, solicitó iniciar su análisis conmigo debido a sentimientos de desesperación crónica y desesperanza, que habían empezado a impregnar su vida laboral. Lo último siempre había servido de fuente primaria para sus sentimientos de auto-estima y vitalización, pero ahora había perdido el lustre. Varios de sus "viejos fieles" clientes habían llevado sus negocios a otra parte, dejándola, sintiéndose herida, traicionada y propensa a encolerizados estallidos de ira alienante.

Los estallidos, aunque eran una parte familiar de su historia, habían estado más controlados en los últimos años. Atribuía este control al Prozac que tomaba desde "La Gran Depresión" como ella lo llamaba, que había ocurrido hacía unos cinco años, cuando estaba en terapia con un individuo más encantado con la vida "glamorosa" de Gayle que en ser consciente de, o cuidar su deteriorada condición psicológica. Ahora Gayle estaba perdiendo el control y sus actuales sentimientos parecían ser una reminiscencia de aquellos vividos justo antes de "La Gran Depresión". Una amiga la animó a probar el psicoanálisis, y con una clara ambivalencia, inició el proceso.

La mayor de ocho hermanos, Gayle creció en un estricto hogar católico desprovisto de auxilio y apoyo emocional. Su madre era una mujer crítica, exacta y sin humor que servía a su padre diligentemente con un aura de furia silenciosa y resentimiento. Su padre era mayormente distante excepto cuando se le pedía que propinara dura disciplina física, lo que continuó incluso en su adolescencia. Las relaciones hostiles entre ella y su padre continuaron hasta su muerte hacía ya unos 20 años.

Gayle fue hija única los primeros cinco años de su vida. Tiene el recuerdo de estar sentada en su jardín, sintiéndose a gusto con el sol brillando sobre ella. De pronto alguien sale, las nubes tapan el sol y el jardín de golpe se hace sombrío, y desde entonces la vida se torna gris y triste. Este recuerdo sirve de plantilla para su sensación crónica de que la tristeza o la pérdida prevalecerán sobre cualquier posibilidad de alegría.

Las relaciones íntimas generalmente la esquivan. Varias relaciones íntimas con hombres a lo largo de los años terminan al poco de empezar. Vive cada ruptura como devastadora e incapacitante. De hecho, en los últimos ocho años se había jurado mantenerse alejada de los hombres. Y pocas relaciones con mujeres han perdurado.

Gayle es alta, delgada y extremadamente atractiva de una forma un tanto severa. Siempre viste elegantemente y entra en la habitación con un aire de seguridad y superioridad mientras su ojo siempre-vigilante y crítico me escruta, a mí y al entorno. Nunca deja de expresar su desaprobación, normalmente en tonos cínicos y cortantes. 
Sin embargo, cuando se relaja, emana encanto, con un maravilloso y agudo sentido del humor que me cautiva. En nuestros primeros días juntas, con frecuencia me encontraba oscilando entre intensos sentimientos de ternura y de repulsa hacia ella. Llegamos a entender que parte de su híper-vigilancia surgía de su necesidad de medir mi fiabilidad, mi capacidad de comprender y apreciarla, mi capacidad de seguir sintonizada con sus fluctuantes estados de humor, y se fue relajando un poco. De la misma forma, yo también empecé a relajarme más, lo que facilitaba una conexión más firme y nos permitió proseguir con una mayor sincronización. Sin embargo, a día de hoy sigue siendo exquisitamente sensible a mi "humor" y "nivel de energía" como dice ella. Si le parece que mi "energía" no está en sintonía, ella se pone tensa, o simplemente se queda impávida y se retrae.

Enseguida en el análisis surgió un inquietante patrón. Después de una sesión especialmente buena, ella cancelaba la siguiente, minutos antes de la hora de inicio. Esto parecía consistente con otras situaciones en su vida, en las cuales se retiraba antes de la decepción o rechazo que continuamente anticipaba. Cuando surgía la esperanza en nuestras sesiones, enseguida cedía ante la sensación de temor de que estas buenas sensaciones se frustrarían, lo que hacía que se retirara. Su retiro era literal. Se quedaba en cama y permanecía allí hasta sentir que estaba lista para asistir a nuestra siguiente sesión.

Surgió que su apartamento, su lugar de retiro, nunca lo había visitado nadie. Lo describía como una pocilga, inadecuada para ser habitado por ningún humano. Era el templo de su desesperación - un lugar privado que reflejaba sus peores sentimientos sobre sí misma. Resaltaba con un claro contraste con su elegante presentación personal, su amor por la belleza y los objetos lujosos, y su lugar en el campo - un lugar de orgullo, belleza y placer - un lugar que alegremente compartía con otros - un lugar de esperanza de lo que ella podría llegar a ser.

Tras meses de este patrón, dejó un mensaje en mi contestador afirmando que estaba desperdiciando el tiempo de ambas, que este proceso nunca funcionaría y que no iba a regresar. Tras alguna deliberación - quizás yo también me sentía desesperada y lista para retirarme - la llamé y le dije que mientras yo debía aceptar su decisión, sentía que esto era otra variación del tema de esperanza/temor y que deberíamos hablar más sobre ello. Animada por mi "persecución", decidió continuar con el análisis. Siguió un periodo productivo en el cual ella relató más recuerdos, estuvo más vital, funcionaba mejor en el trabajo, y empezó a concebir nuevas posibilidades para asegurar su carreraun área que se había sumido en la desilusión y el pesimismo. 
Algunas semanas después no apareció a su sesión. Era la primera vez que se ausentaba sin tan siquiera una llamada. La llamé, dejé un mensaje, pero no recibí ninguna respuesta. Tras la cuarta sesión seguida sin aparecer, la volví a llamar, dejando mensajes tanto en su casa como en su trabajo. Seguía sin respuesta. Me sentía despreciada e irritada, sentimientos que se intensificaron cuando un par de días después, recibí un mensaje suyo en mi contestador. Su voz tenía esa particular cualidad superior y animada que adopta cuando se dirige a seres inferiores. Sin duda me sentía como tal en ese momento. Ni una palabra de disculpa acompañó a su pronunciamiento de que acudiría a nuestra siguiente sesión. No estaba segura de cómo manejar la situación. Expresar mi ira no parecía productivo. Y no expresarla parecía cobarde. Me sentía molesta, poco apreciada y estaba preocupada de que mi esperanza por nuestro trabajo conjunto se estaba socavando de forma desalentadora. Insegura de cómo proceder, esperé a nuestra siguiente sesión.

Gayle entró arrolladora, en su antigua forma altanera, y se sentó en la silla y no en el diván. Me ofreció una disculpa formal por no haberme informado, pero añadió que había entrado en un retiro de tal magnitud que no tenía la energía suficiente ni para hacer una llamada. Ofreció su viejo razonamiento de que se había estado sintiendo mejor y que al sentirse no merecedora de esas buenas sensaciones, se había retirado a su cama. La escuché silenciosa mientras hablaba. Mientras la escuchaba mi propia ira se disipó, y conecté más con su profunda sensación de soledad. Cuando terminó, sencillamente afirmé, "Debe ser muy duro creer que realmente me importas, y que cuando te retiras y te aíslas, te sientes tan sola y tan poco merecedora de amor, que no es posible imaginar que sigo aquí, que me importas". Empezó a llorar por primera vez desde que trabajábamos juntas. Esta fue una sesión importante que anunció un amplio e ininterrumpido periodo del análisis, durante el cual se involucró románticamente con un hombre. Los extractos que presentaré los extraigo de las sesiones de este periodo - a principios del segundo año de análisis.

\section{SESIÓN 1: MIÉRCOLES}

Gayle entra tranquilamente con aspecto animado y contenta. Poco después de sentarse en el diván comienza a hablar.

Gayle: Esto de una relación es algo bueno - es algo tangible que muestra mi movimiento - estoy orgullosa de mí misma. He confiado en mis sentimientos y he seguido adelante 
con esta experiencia. Él, como tú, se ha colado por debajo de mi radar, y estoy contenta de haber tenido esta experiencia.

X: ¿Haber tenido?

Gayle: Nunca espero que las cosas duren. No hubiera podido tener esta relación anteriormente. Estoy tratándolo de forma diferente de todo lo demás. Después de haber construido todo tipo de muros conocidos a la humanidad - incluso encontré algunos extra y algunas trincheras (nos reímos) - seguí adelante con ello. Me siento segura con este hombre. No sé si soy yo o él. Creo que soy yo. ¡Dios mío! Creo que debo haber tenido lo equivalente a 10 años de frustración sexual - es muy bueno. No tiene nada de dinero... estoy intentando que eso no me moleste. Simplemente me estoy dejando... pero no quiero que nuestras sesiones sean todo sobre esto. No quiero que estas sensaciones que estoy teniendo desaparezcan cuando este hombre se marche. Aún tengo tanto trabajo por hacer. Nunca he estado en este lugar antes y estoy realmente orgullosa de mí misma.

X: Ha tardado mucho en llegar.

Gayle: Eso si que es cierto. He sido tan dura conmigo misma. Me siento segura con él... estoy empezando a sentir que por fin puedo respirar. Él dirige una revista en nuestro negocio... probablemente llevamos unos 20 años viéndonos. Nunca me fijé en él... me parecía un perdedor... un hombre sin dinero y demasiado tierno. ... Deja ver sus sentimientos ... Ahora me gusta. Me ayuda a expresarme con mayor facilidad. (Después de una pausa y con una voz más sobria continúa.) Mi madre acaba de regresar de Hawai... incluso se lo ha pasado bien. Aún tengo este temor de que me voy a convertir en mi madre... nunca perdonaré cómo trató a sus hijos. Pienso en su aversión a los hombres desde la muerte de mi padre. Mírame a mí durante los últimos ocho años. Temo ser más como ella de lo que creo. Su vida ha estado gobernada por el miedo... y creo que lo mismo es aplicable a mí. Sólo quiero ser yo... he llegado a estar lo más cerca de serlo en estas últimas semanas. Estoy menos asustada. Nunca había tenido una relación que durara más de seis meses con nadie. Por primera vez, tener estos sentimientos no me hace sentir débil.

(En este punto, yo estaba menos convencida de sus decrecientes temores y dudas... a pesar de su emoción, parecía que faltaba algo.)

X: ¿Él aún sigue en el armario?

Gayle: ¡Oh sí! (mucha risa). Me conoces demasiado bien. Aún ni le dejo llamarme a la oficina. (Las dos nos reímos. Se torna más pensativa). Aún siento vergüenza de no 
conseguir a un hombre que se gane bien la vida. ¿Cuál es el valor de una persona así? Esto ahora es sólo un pequeño incordio... antes era más intenso. Creo que simplemente se me acabaron los muros.

$\mathrm{X} \quad$ Eres demasiado creativa para quedarte sin muros mientras los necesites.

Gayle: Sí (se ríe). Me ha enseñado cómo confiar y abrirme a otra persona.

X: $\quad$ Quizás es algo que te estaba empezando a ocurrir en todo caso.

Gayle: Quizás. Es como nuestro boletín de evaluación.

\section{SESIÓN 2: JUEVES}

Gayle prácticamente irrumpe en mi oficina. Mirando intensamente, se tira en el diván, emite varios largos suspiros y en un tono muy "razonable" comienza:

Gayle: Me siento muy calmada y clara... pero ya me dirás... lo harás en todo caso... siempre lo haces. Este hombre entra en mi vida, abre mi corazón... pero no es el hombre adecuado para mí. Y no siento un interés real en él.

X: ¿Desde cuándo?

Gayle: Ayer... yo quería avanzar y encuentro esto con un hombre que dura bastante tiempo. Esto me sorprende completamente... siempre me sentiré agradecida y le recordaré con cariño... pero eso es todo. No quiero volver a tener sexo con él. Quiero la sensación que he tenido con él... la sensación de seguridad, pero con el hombre adecuado. ¡Esto lo dice la virgen que ha nacido de nuevo 3 tumbada en tu diván! (Continúa, aunque suena demasiado razonable y bastante desconectada). Este fue el maravilloso momento que abrió mi corazón. No tengo mucho que decir al respecto. No tengo ningún pensamiento real. Simplemente está claro. La interacción está completada.

X: ¿Hay alguna posibilidad de que éste pueda ser otro ejemplo en el que te cierras cuando sientes que algo te agrada antes de que se ponga feo y te haga daño?

Gayle: No lo sé. Eres tú quien hace la pregunta... intelectualmente, es una posibilidad. No llego a conseguir reunir ningún pensamiento o emoción sobre el tema. Simplemente está claro. (A mi me parecía que "claro" era una desconexión emocional, correlacionándolo con mi experiencia de ella durante esta sesión... me di cuenta de mi propia sensación de distanciamiento y que en ese momento me estaba sintiendo menos

${ }^{3}$ N.de T.: Hace un juego de palabras a partir de "Cristianos renacidos" (grupo religioso) 
conectada. Después de un rato añadió) no se si esto tiene algo que ver o no, pero creo que él está un poco enamorado de estar enamorado... nada que ver conmigo... como ese acosador en mi vida justo antes de "La Gran Depresión". No hay nada con lo que conectar y me siento aburrida. Sé que no te gusta esa palabra.

X: $\quad$ Me parece bien la palabra una vez entienda más específicamente a qué se refiere. Gayle: Tiene toda nuestra vida planificada... vivir juntos... casarnos... y todo esto sin ninguna aportación mía. Lo siento como el acosador.

X: $\quad$ No sé mucho sobre el acosador.

Gayle: Realmente nunca lo hemos hablado. Fue próximo a la época de La Gran Depresión. Había estado durante semanas imaginándome al hombre perfecto de mi vida - amoroso, sensible, espiritual, autosuficiente etc. Estaba emitiendo energía para atraer a un hombre así. Apareció un hombre - físicamente no era mi tipo - un médico. Empezamos a salir. Evité el sexo por un tiempo. A nivel físico no me sentía atraída. Sexo.... La primera vez - ¡Agh! ¡Agh! ¡Agh! ¿Quieres que termine la sesión con esta nota? (Risa. En tonos muy dramáticos y mucha gesticulación) Seguimos... empezamos a hacer el amor en el suelo... él encima... empezó a sudar como las cataratas de Niágara y a oler. ¡Fue espantoso y repugnante! Tuve que parar. Finalmente, después de varias semanas, él planificando nuestras vidas juntos y yo evitando el sexo, le dije que no podíamos ser amantes, ni tan siquiera amigos. Respondió sugiriendo que nos acostáramos, que me sentiría mejor con todo. ¡Me fui! A continuación empezaron sus incesantes llamadas, mensajes desagradables, y golpes en mi puerta a cualquier hora. Finalmente llamé a la policía. Me sentía culpable porque le había imaginado y atraído hacia mí. Hay ciertos aspectos similares en el Sin-nombre (yo le había puesto este apodo cuando durante un tiempo no me ofreció ningún nombre. Después, cuando ya había revelado su nombre, ella prefirió éste y nos quedamos con él.) Hablé con él y le dije bastante abiertamente que necesitaba sentir las cosas de forma más personal - más sobre mí. ¿Crees que me habrá escuchado?

$\mathrm{X}$ : Supongo que lo averiguaremos.

Gayle: (Se ríe). Así que terminamos cuando tú consigues todos los detalles interesantes.

\section{SESIÓN 3: LUNES}

Con aspecto un tanto crispada, me reta sarcásticamente con, "Supongo que el anterior a mí era alguien especial - le has dado cinco minutos extra". La miro con curiosidad ya 
que mi sesión previa había terminado a su hora, 15 minutos antes de la suya. Gayle entra normalmente, marchandose exactamente a su hora. Por tanto, perpleja pensé en qué es lo que podía haber visto. Y también me sentí un poco irritada - ¿cuánto será lo suficiente para hacerla sentir que tiene un lugar conmigo? Se tumbó y dijo, "Sólo te estaba tomando el pelo."

X: Quizás.

Gayle: (Aparentemente irritada por no extenderme más con esto.) En fin. (suspiro). Después de estar tumbada rígidamente, con los brazos cruzados, músculos faciales en tensión y en silencio por un tiempo: Este fin de semana leí "Las palabras para decirlo" (The Words to Say It) (el libro escrito por María Cardinale relatando la experiencia de su propio psicoanálisis). Cardinale lo llama la COSA. Yo lo llamo la FOSA 4 . Sentía que yo era más capaz de afrontar la FOSA que mi madre - de alguna manera le fallé a mi familia porque yo fui capaz de salir del agujero. Mi madre nunca pudo abrazarme porque le recordaba la fragilidad de todo. Siempre me he visto como otra, aparte de ella... al leer este libro recordé que yo venía de ella. Eso me asustó. Creo que odio a mi madre... no es sólo que no me guste.

X: (Preguntándome hasta qué punto el que yo no conectara con su necesidad de reafirmación de que ella es "especial" al principio de la sesión, ha suscitado a su madre retraída que constantemente negaba que ella era especial.) Quizás el que yo no te haya contestado más completamente al principio de nuestra sesión te haya dejado sintiéndote herida y poco especial - sentimientos que has vivido muchas veces con tu madre.

Gayle: Hmmmm. Eso es interesante... no lo creo. Creo que están empezando a filtrarse cosas de ese libro. (Toda su actitud conmigo era de "Si yo he tenido que sufrir, tú también".) (Está muy agitada en este punto.) ¿Qué es esto que hay entre mujeres? Mi madre siempre me ha visto como una rival. ¿Cómo perdonas a alguien que ni siquiera ve que te ha hecho mal? Creo que el proceso de separación con mi madre lleva más tiempo de lo normal - todos mis sueños tienen lugar conmigo viviendo en casa de mis padres. Creo que aún hay temas sobre la separación. La veo y me pregunto por qué quiere seguir viviendo. Odia a todos y a todo - y sin embargo no creo que entre en su cabeza la posibilidad de finalizar su vida. (Su tono estridente empieza a dar paso a una voz más calmada, triste.) Yo acabaría con mi vida si se pareciera en algo a la suya. Quizás si vive lo suficiente, conseguiré alguna retribución - algún reconocimiento de que algo que dije

\footnotetext{
${ }^{4}$ N.de T.: En el original figura el término PIT expresa. Este material es para uso científico y profesional exclusivamente y puede contener información clínica sensible. Los editores no se responsabilizan de los contenidos de los autores. Dirigir las consultas sobre derechos y autorizaciones a ceir@psicoterapiarelacional.es
} 
o hice estaba bien. Eso nunca ocurrirá. No tenía ninguna sensación de que yo tuviera ninguna necesidad... me pregunto si ella alguna vez ha pensado que haya tenido necesidades. Se casó a los 19, yo nací 10 meses después y estuvo embarazada los siguientes 50 años. Me pregunto si esto agotó su sexualidad. Aquí hay una mujer que inicia su vida sexual con excitación, para pasarse la vida "potando". Quizás soy yo la que le atribuye cosas ... probablemente lo sea. Si sólo hubiera dicho, que necesitaba unos años sola con su marido o hubiera dado alguna idea de que hubiera deseado estar ahí para mí, o incluso alguna indicación de por qué no pudo. Esto la haría humana. Sin embargo, es sólo una mártir enfadada, descontenta, crítica que asevera que no necesita nada. Dios, me gustaría resolverlo... por un montón de razones. Una, ella va a morir, y me gustaría tener alguna idea de quién es/era. Para ella esta necesidad mía es autoindulgente. No es asunto mío, y no es mi lugar como hija preguntar... Es algo que no elige y "cuál es el sentido de esta discusión en todo caso"- la manera típica suya de zanjar una conversación. Simplemente necesito conocerla mejor.

X: Tu búsqueda de más conocimiento y comprensión sobre ti misma parece enlazada con tu necesidad de conocer más a tu madre. Cuan más evasiva es, más elusivo parece tu propio material.

Gayle: ¡Sí! Ella tiene el poder de no darme lo que yo quiero y necesito. Luego, por supuesto, está el tema de lo que yo no necesito ni quiero. Estuve en el médico el viernes - este querido y cariñoso hombre me ha dado herpes. Ya te imaginarás cómo es esto con mi tema con los gérmenes. Me siento mancillada, sucia, contaminada. Le llamé y le dije que quería clavarle una estaca en el corazón y que no quería volver a verle. La conclusión es que llegado el sábado yo estaba hecha mierda... histérica... no podía soportar la idea de no volver a verle. Y le llamé de nuevo... Hablé desde mi vulnerabilidad y le dije que estaba muy confusa con todo esto. Tuvimos una muy buena conversación. Se disculpó y juró una y otra vez que no había tenido ningún episodio reciente y que no sentía que fuera contagioso (calmándose un poco). Es alucinante que aún quiera continuar con este hombre - que me haya sentido tan impulsada a no dejarlo. No lo puedo comprender. Me sentí mejor después de hablar con él. ¿Cómo puedo decir que esto sea seguridad?... pero lo digo. Ahora le necesito... Por supuesto, esto podría cambiar para nuestra próxima sesión.

$X$ : Parece que su potencial pérdida desencadenó algo importante en ti que te permitió vivir tus emociones de forma más intensamente de nuevo.

Gayle: Creo que es eso. Si te soy sincera, parte de mí, quiere tener todas las opciones quiero que se vayan o irme yo y luego los quiero de nuevo. (gran suspiro). Me siento un 
poco exhausta. Me sorprende cómo me estoy esforzando. Sólo el hecho de las emociones en sí - es una completa sorpresa. He estado entumecida tanto tiempo... no sabía que aún era capaz de tener estos sentimientos. Incluso cómo me esfuerzo en abrirme contigo así. No me puedo creer la facilidad con la que te he contado el tema del herpes. Realmente debo sentirme segura contigo. (Se levanta para marcharse y añade) Ahora, si la próxima vez me recibes con un bote de desinfectante, realmente sabré lo tonta que soy. (Le sonrío tiernamente. Ella devuelve la sonrisa y se marcha tranquilamente).

\section{SESIÓN 4: MIÉRCOLES}

Entra con aspecto relajado y con buenos ánimos, sonriéndome cálidamente.

Gayle: Esto se ha convertido en el momento álgido de mi día. Debemos estar haciendo algo bien. Paso el día esperando esta hora. Aún me siento igual respecto al Sin-nombre. Quizás sea el enfado por el tema del herpes. Sé que le he atacado - y cuando ataco, ¡ataco con fuerza!- Al mismo tiempo no he perdido esa maravillosa sensación que tenía con él al principio. Esta soy yo hablando. Incluso siento que sería posible con otra persona porque hay algo diferente en mí... Pero él ha sido tan útil para nuestro trabajo.

X: ¿Como un atrezo psicoanalítico? (nos reímos mucho.)

Gayle: Bueno, mira el material. Hablar sobre el sexo ha abierto todo tipo de temas emocionales aquí.

X: Quizás logremos por nosotras mismas mantenernos abiertas.

Gayle: Quizás. Te das cuenta de que no le he contado a nadie más, nada sobre él - a nadie. Parece que en cuanto sale de mi vista me retraigo. Esto él lo debe percibir e inunda mi teléfono con mensajes como, "necesitamos pasar más tiempo juntos", "necesitamos trabajar en esto". Trabajar en esto - ese el problema. Es como una relación de Nuevo Demócrata... tan sincera. Aquí tengo algo para ti. Este tipo tiene un pene realmente hermoso... Él quiere hacer el amor con respeto. Yo quiero follar. Sí, hacer el amor es una parte, pero al principio de una relación ¿no será más el sexo apasionado? Me siento que estoy con un buen cristiano... Alguien que sabe que debe ser respetuoso con las mujeres. Habla mucho sobre lo maravilloso que es hacer el amor con alguien a quien realmente amas. ¡Vale! ¡Vale! Ya hemos tenido la conversación. Quiero un poco de diversión. Esto suena superficial, pero no es eso lo que quiero decir. Aún estoy agradecida de que haya podido colarse por debajo de mi radar y abierto de nuevo mi corazón... Ahora estoy lista para tener un novio. Me siento una mierda. Es una buena 
persona y yo me estoy poniendo quisquillosa. Mi madre diría que debería superarlo. "Querida, todos debemos hacer sacrificios en la vida". No quiero hacerlo. Es como estar subyugada por nada. Sé que aún no tengo que tomar una decisión en un sentido u otro ... así que de momento seguiré adelante ... Parece estar conforme con eso. Ni siquiera se pregunta por qué aún no le he invitado a mi apartamento. Allí hay tanta energía negativa. ¡Es realmente horroroso! De alguna forma este lío que he creado es parte de mí. Tan distinto de mi sitio en el campo... mi sitio de belleza... mi sitio ¡Oh! y ¡Ah!.

$X: \quad$ Parecen representar dos importantes aspectos de ti misma que tienes que mantener separados el uno del otro.

Gayle: Es como que mi apartamento es mi sitio de fracaso como ser humano. La gente realmente estaría horrorizada. En el otro sitio me deleito. Sin embargo aún estoy agarrándome a algo en el apartamento. De muchas maneras soy como una niña pequeña delimitando y reclamando mi espacio y asegurándome de que no hay lugar para nadie más. Quizás sólo sea una expresión de mí. Una que necesito. Está bien excepto que es un pequeño secreto sucio... y nadie se atreve a conocerlo. Se ha salido de mi control. Mi sitio en casa refleja quien soy.

X: ¿Y esa es?

Gayle: Fuera de control y asustada (se vuelve callada y pensativa). Siento que esto tiene que ver con la gente. De alguna forma aún necesito mis pequeños secretos sucios. Incluso cuando pensaba en el suicidio, sentía que no podía porque mi madre se moriría si viera el desastre.

X: $\quad$ Mantener el desastre es una forma segura de mantenerla lejos.

Gayle: Si, junto con todos los demás. Nadie sabe esa parte de mí.

X: Sin embargo, parece que estás cada vez más cómoda dejándome entrar en este aspecto. Claro que lo digo asumiendo el riesgo (las dos nos reímos).

Gayle: Supongo que ahora saldré corriendo. ¿Te dije que me voy a ir un mes o dos?

La sesión finaliza con risa y calidez mientras valoramos lo lejos que hemos llegado del ciclo de esperanza/temor/huida.

Original recibido con fecha: 8/5/2021 Revisado: 14/9/21 Aceptado: 30/09/2021 